ARTICLE

\title{
Nickel(II)-catalyzed living polymerization of diazoacetates toward polycarbene homopolymer and polythiophene-block-polycarbene copolymers
}

Li Zhou ${ }^{1,2}$, Lei Xu, ${ }^{1,2}$ Xue Song ${ }^{1}$, Shu-Ming Kang ${ }^{1}, \mathrm{Na} \mathrm{Liu}^{1} \&$ Zong-Quan Wu (i) ${ }^{1 凶}$

Diazoacetate polymerization has attracted considerable research attention because it is an effective approach for fabricating carbon-carbon (C-C) main chain polymers. However, diazoacetate polymerization based on inexpensive catalysts has been a long-standing challenge. Herein, we report a $\mathrm{Ni}(\mathrm{II})$ catalyst that can promote the living polymerization of various diazoacetates, yielding well-defined $\mathrm{C}-\mathrm{C}$ main chain polymers, polycarbenes, with a predictable molecular weight $\left(M_{n}\right)$ and low dispersity $\left(M_{w} / M_{n}\right)$. Moreover, the Ni(II)-catalyzed sequential living polymerization of thiophene and diazoacetate monomers affords interesting $\pi$-conjugated poly(3-hexylthiophene)-block-polycarbene copolymers in high yields with a controlled $M_{n}$, variable compositions, and low $M_{w} / M_{n}$, although the structure and polymerization mechanism of the two monomers differ. Using this strategy, amphiphilic block copolymers comprising hydrophobic poly(3-hexylthiophene) and hydrophilic polycarbene blocks are facilely prepared, which were self-assembled into well-defined supramolecular architectures with tunable photoluminescence.

\footnotetext{
${ }^{1}$ Department of Polymer Science and Engineering, School of Chemistry and Chemical Engineering, and Anhui Key Laboratory of Advanced Catalytic Materials and Reaction Engineering, Hefei University of Technology, Hefei 230009 Anhui Province, China. ${ }^{2}$ These authors contributed equally: Li Zhou, Lei Xu.

凶email: zqwu@hfut.edu.cn
} 
C arbon-carbon (C-C) main chain polymers represent a significant class of polymeric materials that are widely used in daily lives ${ }^{1,2}$. These polymers are typically synthesized via vinyl polymerization through the consecutive addition of $\mathrm{C}=\mathrm{C}$ bonds, facilitating the construction of the $\mathrm{C}-\mathrm{C}$ backbone from the two carbon units ${ }^{3-5}$. Diazoacetate polymerization has attracted considerable research attention as an effective approach for fabricating $\mathrm{C}-\mathrm{C}$ polymers because it is complementary to the aforementioned method ${ }^{6-10}$. The resulting polycarbenes with a polar substituent on each backbone atom are difficult to synthesize using traditional Ziegler-Natta catalysts and other transition metal catalysts ${ }^{11,12}$. Owing to the unique structural characteristics of polycarbenes, they exhibit distinct properties such as enhanced stability, solvent resistance, environmental compatibility, and easy processibility ${ }^{6-10}$.

To date, synthetic approaches and catalytic systems for diazoacetate polymerization are very limited. The living polymerization of diazoacetates is a long-standing challenge in the synthetic chemistry community ${ }^{13-15}$. Rhodium and palladium complexes are the most used catalysts for diazoacetate polymerization, developed by de Bruin et al. ${ }^{7,9,16}$, Theato et al. ${ }^{17,18}$, and Ihara et al. ${ }^{19-21}$. For example, rhodium-diene catalysts can be used to fabricated polycarbenes with a high molecular weight $\left(M_{\mathrm{n}}\right)$ and tacticity ${ }^{17,22-25}$. Palladium(II)-based catalysts are effective catalysts for various diazoacetate polymerizations and commonly yield atactic polycarbenes with a medium-to-high $M_{\mathrm{n}}{ }^{26-28}$. Remarkably, using a Pd(II) catalyst, the polymerization of a unique diazoacetate monomer with a bulky cyclotriphosphazene substituent followed a quasi-living fashion, although the degree of polymerization (DP) was not very high ${ }^{29}$. Very recently, we reported a $\pi$-allyl PdCl catalyst with a steric bidentate phosphine ligand, which can polymerize various diazoacetates in a living manner, affording expected polycarbenes in high yields with a controlled $M_{\mathrm{n}}$ and low dispersity $\left(M_{\mathrm{w}} / M_{\mathrm{n}}\right)^{13,14}$. Thereafter, Toste and coworkers reported a binuclear Pd(II) catalyst that can initiate the quasi living polymerization of diazoacetates ${ }^{15}$.<smiles>[R]OC(=O)C=[Ni]</smiles>
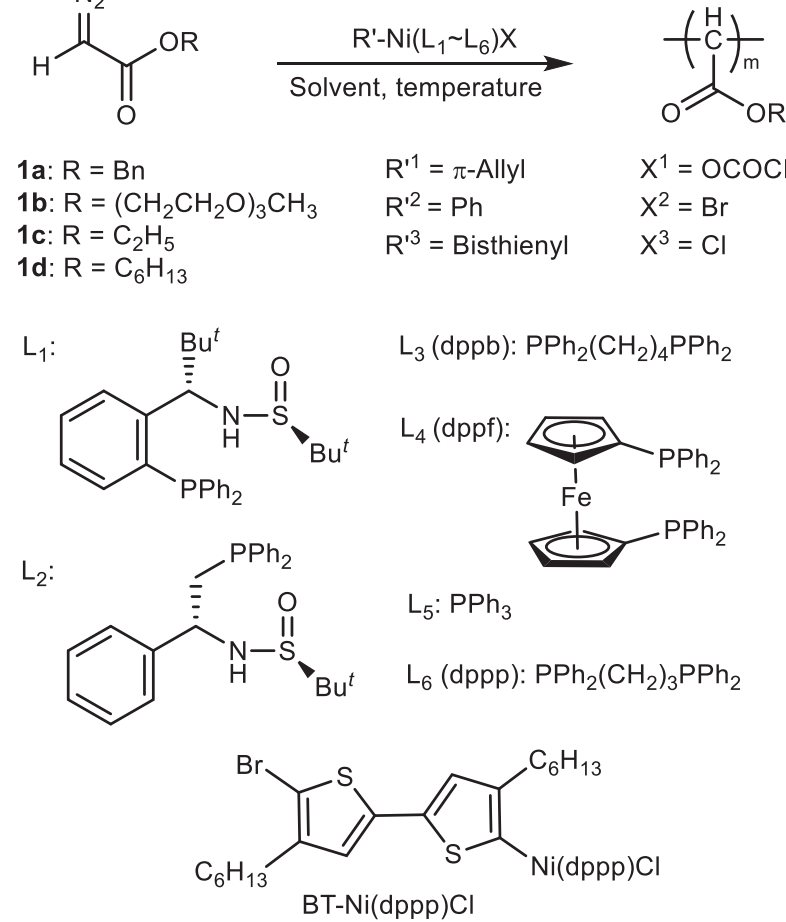

Fig. 1 Reaction scheme. Polymerization of monomer 1a-1d using $\mathrm{R}^{\prime}-\mathrm{Ni}\left(\mathrm{L}_{1}-\mathrm{L}_{6}\right) \mathrm{X}(\mathrm{L}=$ Ligand $)$.
Although significant advances have been achieved in diazoacetate polymerization, the catalysts/initiators used are still limited to expensive palladium and rhodium complexes. Other metal complexes, particularly non-noble metal catalysts, have rarely been reported for diazoacetate polymerization. Therefore, developing inexpensive catalysts/initiators for living diazoacetate polymerization is greatly desired. Nickel catalysts have been widely used in the synthesis of polymers, such as in the controlled radical polymerization of olefins and the catalyst-transfer polymerization (CTP) of aryl monomers for preparing $\pi$-conjugated polymers $^{30,31}$. The use of inexpensive nickel complexes for diazoacetate polymerization is also essential. However, the reported nickel-catalyzed diazoacetate polymerization generally affords oillike oligomers ${ }^{32,33}$. The $\pi$-conjugated poly(3-hexylthiophene) (P3HT) is a type of useful semiconductor material and has garnered broad research attention in recent years owing to its intriguing optoelectronic applications ${ }^{34,35}$. Incorporating polycarbenes into P3HT to form a block copolymer can control the self-assembly morphology of $\mathrm{P} 3 \mathrm{HT}$, thereby affording functional materials with great potential in electronics and photonics, lightemitting devices, bioimaging, etc ${ }^{36-44}$. Therefore, the controlled synthesis of P3HT-block-polycarbene copolymers is worthy of investigations.

In this work, we report a $\mathrm{Ni}(\mathrm{II})$ catalytic system for living diazoacetate polymerization, affording well-defined polycarbenes with predictable $M_{\mathrm{n}}$ and low $M_{\mathrm{w}} / M_{\mathrm{n}}$. Furthermore, functional polymers such as $\mathrm{P} 3 \mathrm{HT}$ carrying the $\mathrm{Ni}(\mathrm{II})$-complex terminal can initiate living diazoacetate polymerization, affording $\pi$-conjugated block copolymers with a tunable structure and controlled composition. Taking advantage of this method, amphiphilic block copolymers comprising hydrophobic P3HT and hydrophilic polycarbene were readily synthesized, which were self-assembled into well-defined supramolecular architectures with intriguing photoluminescence.

\section{Results and discussion}

$\mathrm{Ni}$ (II)-catalyzed living polymerization of diazoacetates. A family of $\mathrm{Ni}$ (II) complexes with different substituents and phosphine ligands was facilely prepared via the oxidative addition of bis(1,5-cyclooctadiene)nickel( 0$)$ to aryl halides or $\pi$-allyl trifluoroacetate when different ligands are present in toluene at $25^{\circ} \mathrm{C}$ (Fig. 1). The as-prepared catalysts were immediately used in the following polymerization without isolation and characterization to prevent possible decomposition. To investigate the activity of nickel catalysts, benzyl diazoacetate (1a) was prepared and used in the polymerization. The polymerizations were performed in tetrahydrofuran (THF) at $25^{\circ} \mathrm{C} \quad\left([\mathbf{1 a}]_{0}=0.5 \mathrm{M}, \quad[\mathbf{1 a}]_{0} /\right.$ $\left.[\mathrm{Ni}(\mathrm{II})]_{0}=100\right)$. The polymerization performed using $\pi$-allyl nickel(II) catalysts could only afford oil-like oligomers, regardless of the ligands (runs 1-6, Table 1), whereas some phenyl nickel(II) complexes $(\mathrm{Ph}-\mathrm{Ni}(\mathrm{L}) \mathrm{Br})$ could afford solid polymers. Size exclusion chromatographic (SEC) analysis performed on the $M_{\mathrm{n}}$ and $M_{\mathrm{w}} / M_{\mathrm{n}}$ of the obtained polymers are summarized in Table 1 and Supplementary Fig. 1. The polymers fabricated using $\mathrm{Ph}-\mathrm{Ni}(\mathrm{L}) \mathrm{Br}$ catalysts with appropriate ligands showed a unimodal and symmetrical SEC trace (runs 7-12, Table 1). The $M_{\mathrm{n}}$ and $M_{\mathrm{w}} / M_{\mathrm{n}}$ were $\sim 3 \mathrm{kDa}$ and 1.20 , respectively. This study revealed that an aryl nickel(II) complex can be a catalyst for diazoacetate polymerization. Very interestingly, bisthienyl nickel(II) catalyst (BT-Ni(dppp)Cl) with a diphenylphosphine propane (dppp) ligand showed the best result in the polymerization of 1a among the tested catalysts (runs 13-16 in Table 1 and Supplementary Fig. 2) ${ }^{45,46}$. The recorded SEC peaks of the polymers achieved using $\mathrm{BT}-\mathrm{Ni}(\mathrm{dppp}) \mathrm{Cl}$ were symmetric and unimodal, shifting to a high $-M_{\mathrm{n}}$ region with increasing $[\mathbf{1 a}]_{0} /[\mathrm{Ni}(\mathrm{II})]_{0}$ values (Fig. $2 \mathrm{a}$ 
Table 1 Results for 1a polymerization using various Ni(II) catalysts.

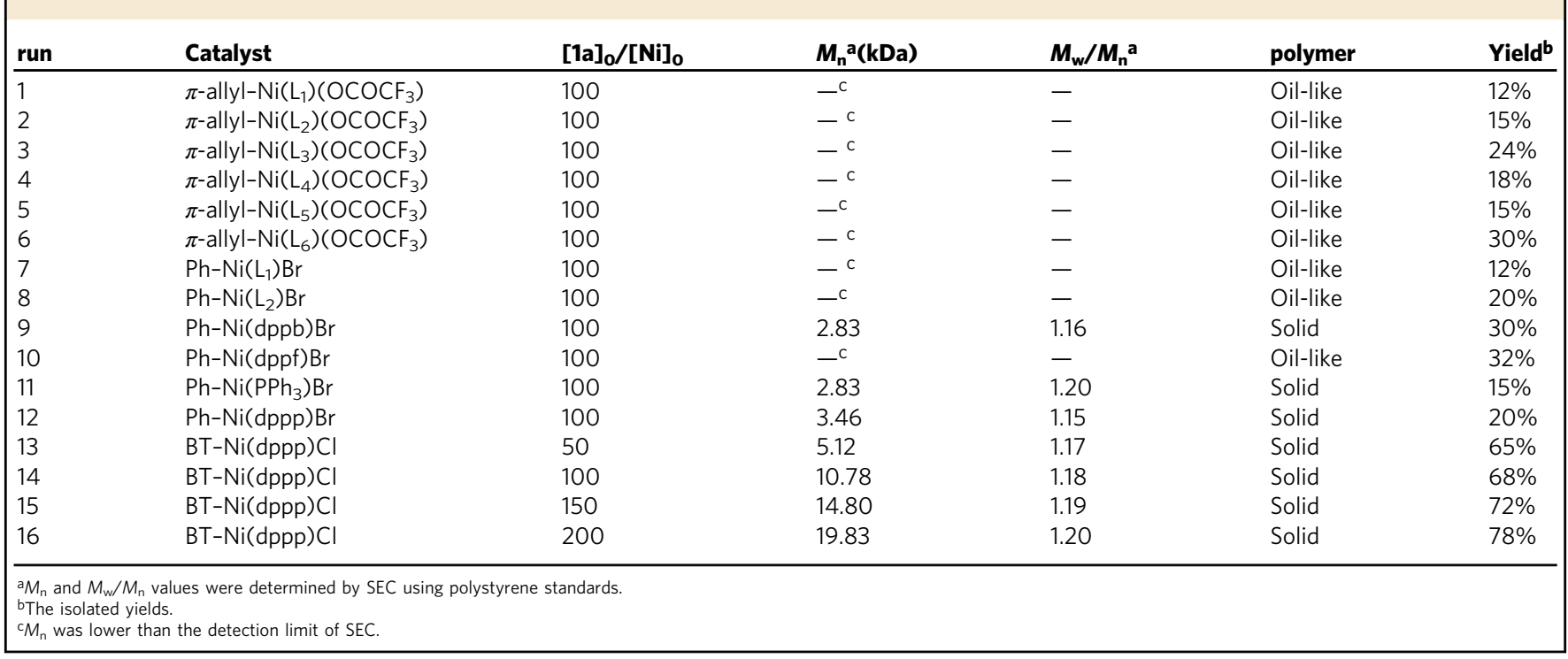
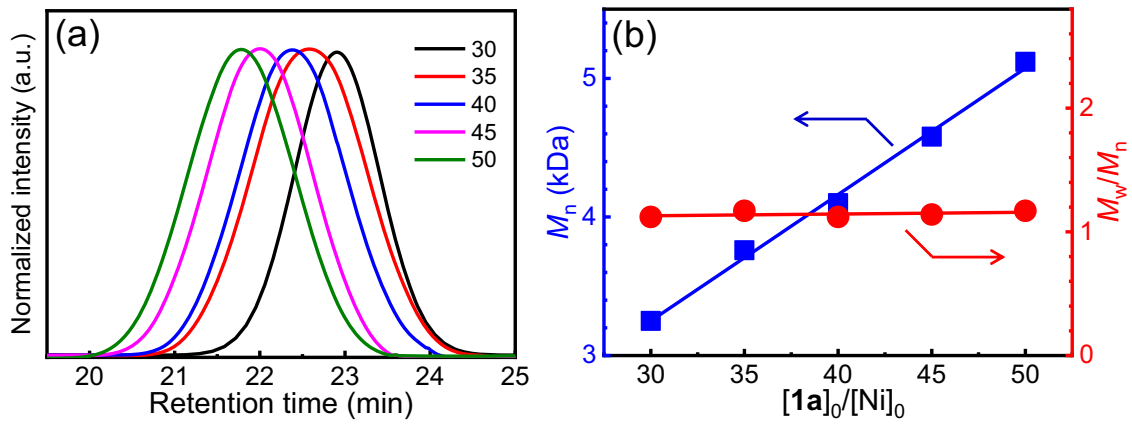

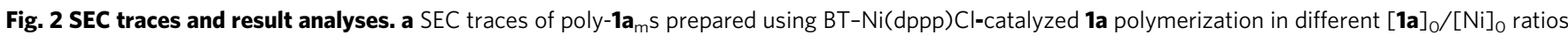
in THF at $25^{\circ} \mathrm{C}$. b Plots of $M_{n}$ and $M_{w} / M_{n}$ of the poly-1a $\mathbf{a}_{m}$ vs. 1a-to-Ni(II) ratio.

and runs 1-4 in Supplementary Table 1). Remarkably, $M_{\mathrm{n}}$ exhibited a linear correlation with the feed ratio of $1 \mathbf{a}$ to the $\mathrm{Ni}(\mathrm{II})$ catalyst, and all yielded polymers exhibited a low $M_{\mathrm{w}} / M_{\mathrm{n}}$ of $<1.20$ (Fig. 2b). These results demonstrate that $\mathrm{BT}-\mathrm{Ni}(\mathrm{dppp}) \mathrm{Cl}$ is an active catalyst for diazoacetate polymerization and may follow a living polymerization mechanism. Notably, the polymerization yield was not very high because the polymers showed good solubility in common solvents, resulting in polymer losses during the isolation process. Next, the polymerization of 1a was performed using BT-Ni(dppp)Cl in different solvents. Interestingly, all polymerizations yielded expected polymers with a controlled $M_{\mathrm{n}}$ and low $M_{\mathrm{w}} / M_{\mathrm{n}}$, except for those performed in chloroform (runs 5-7 in Supplementary Table 1), probably because of the weak acidity of chloroform (run 8 in Supplementary Table 1). Furthermore, the temperature exerted only a slight effect on the polymerization (runs 9 and 10 in Supplementary Table 1). Thus, performing polymerization in THF at room temperature is the ideal condition. Because BT-Ni(dppp)Cl showed good performance in polymerization, it was subjected to careful isolation and complete characterization (Supplementary Figs. 3-10) ${ }^{47}$.

To obtain polymerization details, 1a was polymerized using BT-Ni(dppp)Cl by employing polystyrene (PSt; $M_{\mathrm{n}}=41.4 \mathrm{kDa}$ and $\left.M_{\mathrm{w}} / M_{\mathrm{n}}=1.02\right)$ as the internal standard $\left([\mathbf{1} \mathbf{a}]_{0} /[\mathrm{Ni}]_{0}=100\right)$. The polymerization was monitored using SEC to determine the monomer conversion as well as the $M_{\mathrm{n}}$ and $M_{\mathrm{w}} / M_{\mathrm{n}}$ data of the yielded polymers. As expected, the yielded polymers exhibited unimodal elution peaks in the SEC trace and continually shifted to high- $M_{\mathrm{n}}$ regions during the polymerization process (Fig. 3a). More than $85 \%$ of $1 \mathrm{a}$ was polymerized within $5 \mathrm{~h}$ (Fig. $3 \mathrm{~b}$ ). The plot of $-\operatorname{Ln}\left([\mathrm{M}] /[\mathrm{M}]_{0}\right)$ as a function of the polymerization time revealed that the polymerization followed the first-order reaction mechanism, and the rate constant was $8.3 \times 10^{-5} \mathrm{~s}^{-1}$. Furthermore, the $M_{\mathrm{n}}$ of the synthesized polymers was proportionally and linearly correlated with the 1a conversion; all fabricated polymers showed a low $M_{\mathrm{w}} / M_{\mathrm{n}}$ of $<1.20$ (Fig. 3c). To further prove the living nature of the polymerization, a new feed of 1a was added to the polymerization solution of the freshly prepared poly-1 $\mathbf{a}_{50}\left(M_{\mathrm{n}}=5.52 \mathrm{kDa}\right.$ and $\left.M_{\mathrm{w}} / M_{\mathrm{n}}=1.19\right)$ in THF at $25^{\circ} \mathrm{C}\left([\mathbf{1} \mathbf{a}]_{0} /[\mathrm{Ni}]_{0}=30\right)$. SEC analyses verified the occurrence of the chain extension because the SEC peak moved to high- $M_{\mathrm{n}}$ regions, maintaining a unimodal elution trace (Supplementary Fig. 11). The $M_{\mathrm{n}}$ increased to $8.47 \mathrm{kDa}$ with $M_{\mathrm{w}} / M_{\mathrm{n}}=1.20$. Collectively, these findings prove the living nature of the diazoacetate polymerization initiated using the $\mathrm{BT}-\mathrm{Ni}(\mathrm{dppp}) \mathrm{Cl}$ catalyst.

Structural characterization. The as-prepared poly- $1 \mathbf{a}_{\mathrm{m}}$ was verified using ${ }^{1} \mathrm{H}$ nuclear magnetic resonance $\left({ }^{1} \mathrm{H}\right.$ NMR), ${ }^{13} \mathrm{C}$ nuclear magnetic resonance $\left({ }^{13} \mathrm{C} N M R\right)$, Fourier transform infrared spectroscopy (FT-IR), and mass spectrometry. Characteristic resonances can be observed in the ${ }^{1} \mathrm{H}$ NMR trace of poly-1a $\mathbf{a}_{20}$ (Fig. 4a). The signals at 7.43-6.85 (e) and 5.11-4.18 (d) ppm were assigned to benzene and benzyl methylene protons, 
(a) Time-dependent SEC

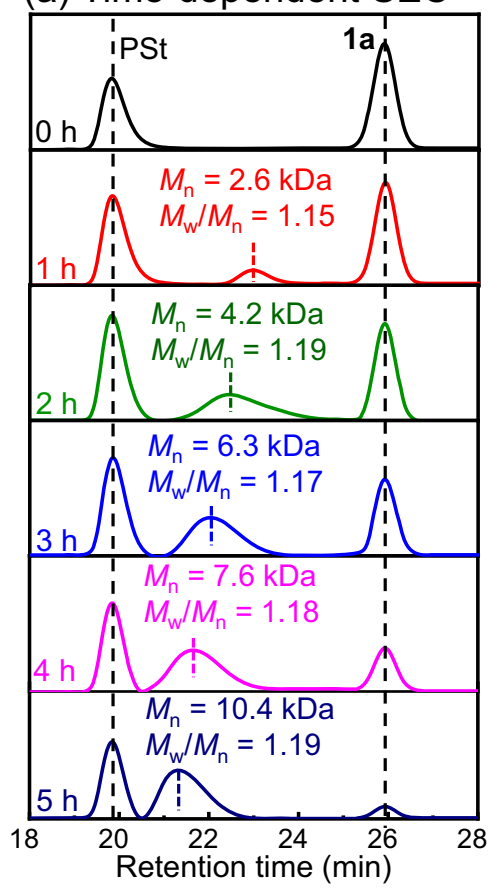

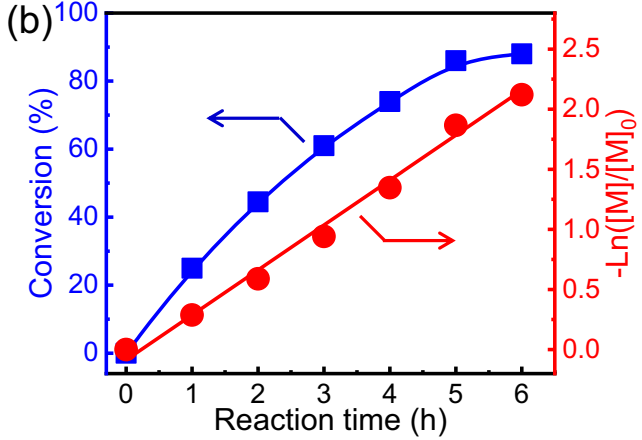

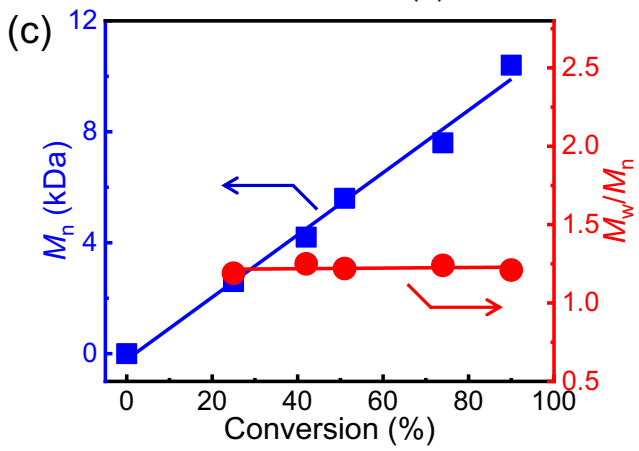

Fig. 3 Time-dependent SEC analyses. a SEC for BT-Ni(dppp) Cl-catalyzed 1a polymerization using polystyrene (PSt) as the internal standard (THF, $25^{\circ} \mathrm{C}$, $\left.[\mathbf{1 a}]_{0} /[\mathrm{Ni}]_{0}=100\right)$. b Plots of $\mathbf{1 a}$ conversion and $-\operatorname{Ln}\left([\mathrm{M}] /[\mathrm{M}]_{0}\right)$ values vs. polymerization time. $\mathbf{c}$ Plots of the $M_{n}$ and $M_{w} / M_{n}$ of the fabricated polymers against $\mathbf{1 a}$ conversion.
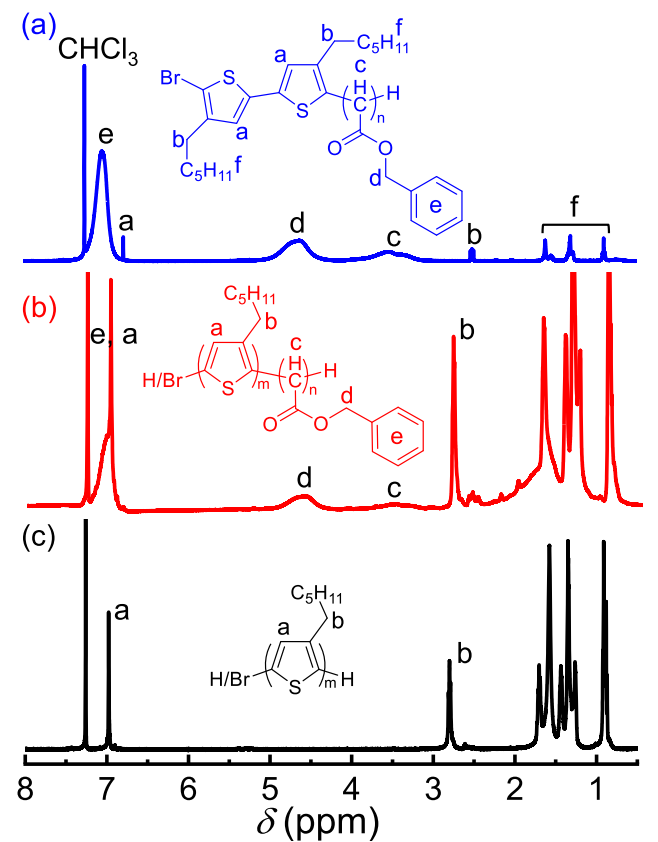

Fig. $4{ }^{1} \mathbf{H}$ NMR spectra. ${ }^{1} \mathrm{H}$ NMR $\left(400 \mathrm{MHz}, \mathrm{CDCl}_{3}\right)$ spectra of poly-12a (a), poly $\left(\mathbf{2}_{20}-b-\mathbf{1 a}_{40}\right)(\mathbf{b})$, and poly-2 20 (c) obtained at room temperature.

respectively. Further, the broad and weak resonances at 3.88-3.02 ppm (c) corresponded to the main chain $\mathrm{CH}$. Moreover, signals attributed to the $\mathrm{ArH}$ and $\mathrm{ArCH}_{2}$ of the terminal BT unit were observed at $6.81(a)$ and $2.51(b)$ ppm, respectively, although they were weak. The DP deduced from the resonances at $6.81 \mathrm{ppm}(a$, ArH of the terminal BT unit) and 3.88-3.02 ppm (c, $\mathrm{CH}$ of the main chain) was $\sim 20$ for poly-1a 20 , generally agreeing with the expected structure. The ${ }^{13} \mathrm{C}$ NMR trace revealed characteristic resonances at $170.2,66.6$, and $46.1 \mathrm{ppm}$, assigned to the carbonyl and $\mathrm{OCH}_{2}$ carbons of the pendants and the $\mathrm{CH}$ carbon of the backbone, respectively (Supplementary Fig. 12). The FT-IR spectrum of poly-1 $\mathbf{1}_{50}$ also verified the formation of the polymer, observed based on the absorption at $1730 \mathrm{~cm}^{-1}$ attributed to the $\mathrm{C}=\mathrm{O}$ vibration (Supplementary Fig. 13). The poly-1a 20 structure was further verified by matrix-assisted laser desorption/ ionization spectroscopy equipped with time-of-flight detection mass spectroscopy, which showed that the highest peak of the 21mer polymer with the BT unit was present at the living chain end (Supplementary Fig. 14). The difference between the adjacent peaks of the mass spectrum was $\sim 148.1 \mathrm{~g} / \mathrm{mol}$, agreeing well with the $M_{\mathrm{n}}$ of the repeating unit. These analyses confirm the formation of the polymers.

Using the BT-Ni(dppp)Cl catalyst, a family of poly-1 $\mathbf{a}_{\mathrm{m}} \mathrm{s}$ with a predictable $M_{\mathrm{n}}$ and low $M_{\mathrm{w}} / M_{\mathrm{n}}$ was facilely synthesized (runs 13-16 in Table 1 and runs 1-4 in Supplementary Table 2). In addition to $1 \mathrm{a}$, the $\mathrm{BT}-\mathrm{Ni}(\mathrm{dppp}) \mathrm{Cl}$ catalyst could catalyze the living polymerization of monomer $\mathbf{1 b}$ with a hydrophilic triethylene glycol monomethyl ether chain and 1c and 1d with alkyl chains of different lengths. All polymerizations afforded desired polymers with the expected $M_{\mathrm{n}}$ and low $M_{\mathrm{w}} / M_{\mathrm{n}}$ (runs 11-14 in Supplementary Table 1 and Supplementary Figs. S15-S23), further confirming the high polymerization activity of the BT-Ni(dppp)Cl catalyst.

Synthesis and characterization of P3HT-b-polycarbene copolymers. Because $\mathrm{BT}-\mathrm{Ni}(\mathrm{dppp}) \mathrm{Cl}$ showed excellent performance in diazoacetate polymerization, functional polymers with a similar $\mathrm{Ni}(\mathrm{II})$-complex terminal may also initiate the living polymerization of diazoacetate, consequently yielding interesting block copolymers. To verify this assumption, 2-bromo-3-hexyl-5chloromagnesiothiophene (2) obtained from 2-bromo-3-hexyl-5iodothiophene was polymerized in-situ using $\mathrm{Ni}(\mathrm{dppp}) \mathrm{Cl}_{2}$ in THF at $25^{\circ} \mathrm{C}\left([\mathbf{1} \mathbf{a}]_{0}=0.50 \mathrm{M},[\mathbf{1} \mathbf{a}]_{0} /[\mathrm{Ni}(\mathrm{II})]_{0}=20\right)$, followed by the CTP or Grignard metathesis mechanism (Fig. 5) $38,45-50$. 
The achieved poly-2 $2_{20}$ showed a $M_{\mathrm{n}}$ of $6.71 \mathrm{kDa}$ with $M_{\mathrm{w}} / M_{\mathrm{n}}=$ 1.19 (Fig. 6a). The polymerization solution was directly treated with a solution of $\mathbf{1 a}$ in THF under dry nitrogen $\left([\mathbf{1 a}]_{0} /[\mathrm{Ni}]_{0}=\right.$ 40). After stirring at room temperature for $24 \mathrm{~h}$, the solution was precipitated into diethyl ether. A P3HT- $b$-polycarbene copolymer poly $\left(\mathbf{2}_{20}-b-\mathbf{1} \mathbf{a}_{40}\right)$ was isolated in $71 \%$ yield via centrifugation.

The recorded SEC trace of poly $\left(\mathbf{2}_{20}-b-\mathbf{1} \mathbf{a}_{40}\right)$ showed a movement to the shorter elution time area compared with that of poly$\mathbf{2}_{20}$ macroinitiator (Fig. 6a); and maintained a unimodal and symmetric peak. The $M_{\mathrm{n}}$ of poly $\left(\mathbf{2}_{20}-b-\mathbf{1 a}_{40}\right)$ was $12.63 \mathrm{kDa}$, higher than that of poly-2 $20\left(M_{\mathrm{n}}=6.71 \mathrm{kDa}\right.$ and $\left.M_{\mathrm{w}} / M_{\mathrm{n}}=1.19\right)$, while the $M_{\mathrm{w}} / M_{\mathrm{n}}$ was as low as 1.18 , indicating that the one-pot hybrid block copolymerization probably proceeded in the living polymerization mechanism. To confirm this hypothesis, a range of block copolymerizations was performed by adding identical amounts of 1a with different amounts of the Ni(II)-terminated poly-2 20 macroinitiator. The correlations between the $M_{\mathrm{n}}$ and $M_{\mathrm{w}} / M_{\mathrm{n}}$ of the produced block copolymers with $[\mathbf{1 a}]_{0} /[\mathrm{Ni}(\mathrm{II})]_{0}$ ratios were plotted in Fig. 6b. As expected, a linear correlation between $M_{\mathrm{n}}$ and $[\mathbf{1 a}]_{0} /[\mathrm{Ni}(\mathrm{II})]_{0}$ was observed and all yielded block copolymers showed a low $M_{\mathrm{w}} / M_{\mathrm{n}}$ of $<1.20$ (Supplementary Fig. 24). This result demonstrates that the block copolymerization of diazoacetates with $\mathrm{Ni}(\mathrm{II})$-terminated P3HT follows a living polymerization mechanism.

The ${ }^{1} \mathrm{H}$ NMR trace of $\operatorname{poly}\left(\mathbf{2}_{20}-b-\mathbf{1} \mathbf{a}_{40}\right)$ showed signals corresponding to both poly- $\mathbf{2}_{\mathrm{m}}$ and poly-1a $\mathrm{a}_{\mathrm{n}}$ blocks (Fig. $4 \mathrm{~b}$ and c). For instance, the resonances of $\mathrm{ArH}$ and $\mathrm{ArCH}_{2}$ for the poly-2 $2_{20}$ segment at $6.91(a)$ and 2.81-2.61 (b) ppm were evident (Fig. 4b). Moreover, the resonance of $\mathrm{CO}_{2} \mathrm{CH}_{2}$ for the poly-1 $\mathbf{1} \mathbf{a}_{\mathrm{m}}$ block at 5.11-4.18 ppm (d) could be detected. Based on the integral analyses of $\mathrm{ArCH}_{2}(b)$ and $\mathrm{CO}_{2} \mathrm{CH}_{2}(d)$ from the poly-2 and poly-1 $\mathrm{a}_{\mathrm{m}}$ blocks, respectively, the ratio of the two blocks was approximately 1:2 for poly $\left(\mathbf{2}_{20}-b-\mathbf{1} \mathbf{a}_{40}\right)$, generally consistent with the feed ratio of the used monomers. The FT-IR spectra also
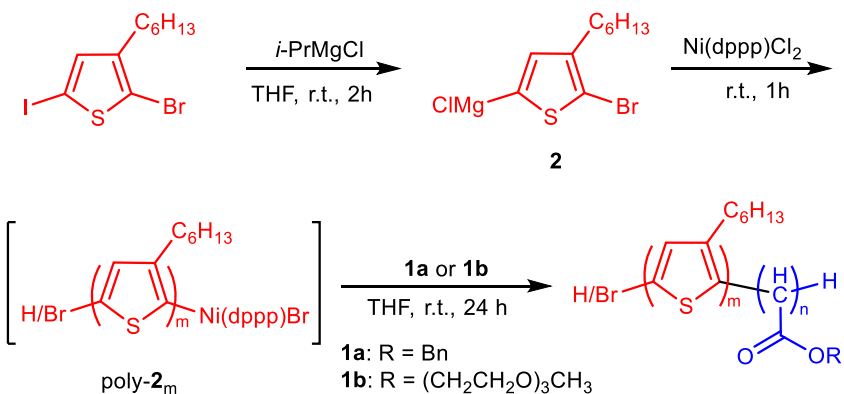

$\operatorname{poly}\left(\mathbf{2}_{\mathrm{m}}-b-1 \mathrm{a}_{\mathrm{n}}\right)$ poly $\left(2_{m}-b-1 b_{n}\right)$
Fig. 5 Synthesis of P3HT-b-polycarbene copolymer. Synthetic route for poly $\left(\mathbf{2}_{m}-b-\mathbf{1}_{n}\right)$ and poly $\left(\mathbf{2}_{m}-b-\mathbf{1} \mathbf{b}_{n}\right)$ copolymers.

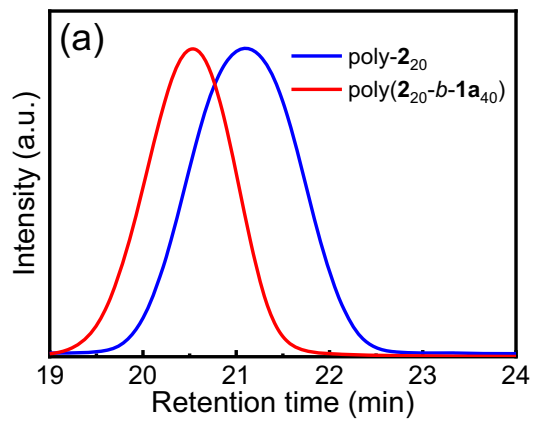

verified the poly $\left(\mathbf{2}_{20}-b-\mathbf{1} \mathbf{a}_{40}\right)$ structure based on the detection of the characteristic vibrations of the two blocks (Supplementary Fig. 25). Collectively, these analyses prove the successful synthesis of the desired P3HT- $b$-polycarbene copolymer and support the one-pot hybrid block copolymerization of thiophene and diazoacetate monomers that follow the living polymerization mechanism, even though the structure and polymerization mechanism of the two monomers differ. Using this copolymerization approach, a family of $\mathrm{P} 3 \mathrm{HT}$ - $b$-polycarbene copolymers with the desired $M_{\mathrm{n}}$ and low $M_{\mathrm{w}} / M_{\mathrm{n}}$ was readily synthesized (runs 1-7 in Table 2 and Supplementary Fig. 26). Moreover, interesting amphiphilic $\pi$-conjugated block copolymer poly $\left(2_{\mathrm{m}}-b\right.$ $\mathbf{1}_{\mathbf{n}}$ )s were facilely obtained using diazoacetate $\mathbf{1 b}$ as the second monomer (runs 8-10 in Table 2 and Supplementary Figs. 27-29). Note that an attempt was made to prepare the block copolymer poly $\left(2_{m}-b-1 a_{n}\right)$ under a reverse sequence by treating the freshly prepared poly-1a $50\left(M_{\mathrm{n}}=5.03 \mathrm{kDa}\right.$ and $\left.M_{\mathrm{w}} / M_{\mathrm{n}}=1.18\right)$ with monomer $2\left([2]_{0}=0.2 \mathrm{M},[2]_{0} /[\mathrm{Ni}]_{0}=20\right)$. However, no chain extension occurred, as revealed by SEC analysis, even the copolymerization was performed at $55^{\circ} \mathrm{C}$ for $48 \mathrm{~h}$. The reason is not very clear; the Grignard reagent 2 possibly preferred to react with the ester pendants of poly-1a $a_{m}$, preventing the chain extension.

Self-assembly of poly $\left(2_{20}-b-1 b_{40}\right)$ copolymer. The self-assembly behavior of the amphiphilic poly $\left(\mathbf{2}_{20}-b-\mathbf{1 b}_{40}\right)$ copolymer was investigated in different solvents. Because of the amphiphilic nature of this copolymer, it can be dissolved in many solvents such as $\mathrm{CHCl}_{3}$, THF, toluene, methanol, and even water. However, the absorption and emission behaviors of this copolymer differ in solvents. Poly $\left(\mathbf{2}_{20}-b-\mathbf{1} \mathbf{b}_{40}\right)$ exhibited a yellow color in THF and a purple-red color in isopropanol (IPA) (Fig. 7a and Supplementary Fig. 30). The ultraviolet-visible (UV-vis) absorption spectra of $\operatorname{poly}\left(\mathbf{2}_{20}-b-\mathbf{1 b}_{40}\right)$ in the THF/IPA mixture are shown in Fig. 7 a. In pure THF, poly $\left(\mathbf{2}_{20}-b-\mathbf{1 b}_{40}\right)$ showed a large absorption in long-wavelength regions, attributed to the P3HT block with the maximum absorption located at $445 \mathrm{~nm}$, similar to the absorption of the P3HT homopolymer. Owing to the absence of the $\pi$-conjugated system, poly- $\mathbf{1 b}_{40}$ showed almost no absorption in the long-wavelength region ${ }^{13}$. When IPA, a polar solvent, was added, the absorption of poly $\left(2_{20}-b-\mathbf{1}_{40}\right)$ at $445 \mathrm{~nm}$ decreased. Further, three new absorption peaks appeared at 511,553 , and $604 \mathrm{~nm}$, indicating the $\pi-\pi$ stacking and crystalline aggregation of the P3HT block (Fig. 7a) ${ }^{35-37}$. The emission of the block copolymer changed in accordance with the absorption change. Poly $\left(\mathbf{2}_{20}-b-\mathbf{1} \mathbf{b}_{40}\right)$ showed a yellow emission of the P3HT block under illumination at $365 \mathrm{~nm}$ in THF, whereas it showed a blue emission in IPA under the same conditions (Fig. 7b and Supplementary Fig. 30). This change was further confirmed by photoluminescent (PL) spectra. When excited at

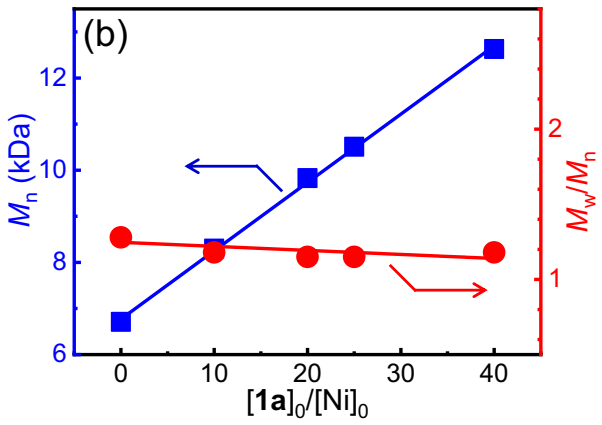

Fig. 6 SEC analyses of block copolymerization. a SEC traces of poly- $\mathbf{2}_{20}$ and the corresponding poly $\left(\mathbf{2}_{20}-b-\mathbf{1}_{40}\right)$ copolymer. $\mathbf{b}$ Plots of the $M_{\mathrm{n}}$ and $M_{\mathrm{w}} / M_{\mathrm{n}}$ data of poly $\left(\mathbf{2}_{20}-b-\mathbf{1} \mathbf{a}_{n}\right)$ s vs. $[\mathbf{1 a}]_{0} /[\mathrm{Ni}]_{0}$ ratio for the copolymerization of $\mathbf{1 a}$ initiated by poly-2 20 with the $\mathrm{Ni}(\mathrm{II})$ complex at the chain end. 
Table 2 Characterization for P3HT-b-polycarbene copolymers.

\begin{tabular}{|c|c|c|c|c|c|c|}
\hline \multirow[t]{2}{*}{ Run } & \multirow[t]{2}{*}{ Polymer } & \multicolumn{2}{|l|}{ poly-2 $\mathrm{m}^{\mathrm{a}}$} & \multicolumn{2}{|c|}{ Block polymer } & \multirow[b]{2}{*}{ Yieldc } \\
\hline & & $M_{n}^{b}(k D a)$ & $M_{w} / M_{n}^{b}$ & $M_{n}^{b}(k D a)$ & $M_{w} / M_{n}^{b}$ & \\
\hline 1 & $\operatorname{poly}\left(\mathbf{2}_{20}-b-\mathbf{1} \mathbf{a}_{40}\right)$ & 6.71 & 1.19 & 12.63 & 1.18 & $71 \%$ \\
\hline 2 & $\operatorname{poly}\left(\mathbf{2}_{20}-b-\mathbf{1} \mathbf{a}_{30}\right)$ & 6.71 & 1.19 & 10.51 & 1.15 & $65 \%$ \\
\hline 3 & $\operatorname{poly}\left(\mathbf{2}_{20}-b-\mathbf{1 a}_{25}\right)$ & 6.71 & 1.19 & 9.83 & 1.15 & $60 \%$ \\
\hline 4 & $\operatorname{poly}\left(\mathbf{2}_{18}-b-\mathbf{1}_{15}\right)$ & 5.86 & 1.20 & 6.58 & 1.19 & $62 \%$ \\
\hline 5 & $\operatorname{poly}\left(\mathbf{2}_{13}-b-\mathbf{1} \mathbf{a}_{10}\right)$ & 4.75 & 1.18 & 5.87 & 1.16 & $68 \%$ \\
\hline 6 & $\operatorname{poly}\left(\mathbf{2}_{18}-b-\mathbf{1 a}_{20}\right)$ & 5.90 & 1.18 & 8.17 & 1.16 & $62 \%$ \\
\hline 7 & $\operatorname{poly}\left(\mathbf{2}_{18}-b-\mathbf{1 a}_{25}\right)$ & 5.90 & 1.18 & 9.17 & 1.17 & $63 \%$ \\
\hline 8 & $\operatorname{poly}\left(\mathbf{2}_{20}-b-\mathbf{1 b}_{40}\right)$ & 6.71 & 1.19 & 10.12 & 1.14 & $72 \%$ \\
\hline 9 & poly $\left(\mathbf{2}_{20}-b-\mathbf{1 b}_{20}\right)$ & 6.71 & 1.19 & 8.25 & 1.18 & $68 \%$ \\
\hline 10 & $\operatorname{poly}\left(\mathbf{2}_{15}-b-\mathbf{1} \mathbf{b}_{20}\right)$ & 4.83 & 1.18 & 7.13 & 1.19 & $62 \%$ \\
\hline
\end{tabular}
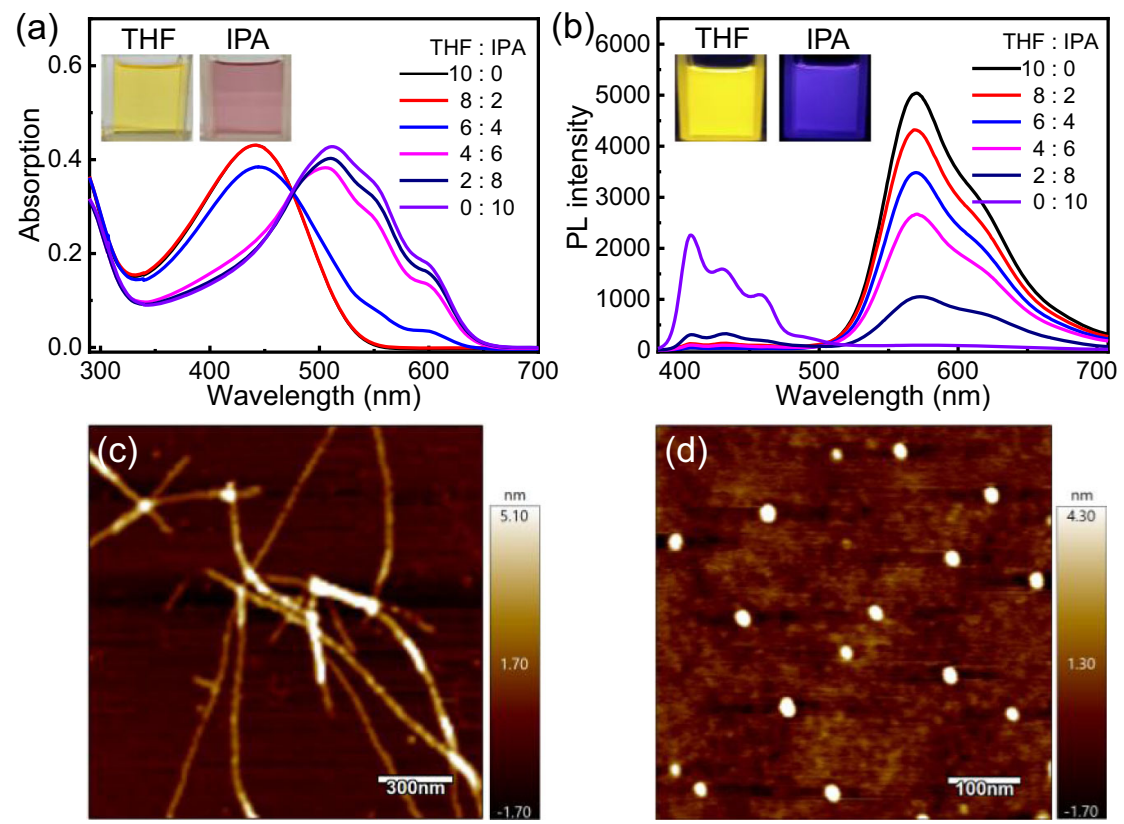

Fig. 7 Absorption and emission spectra as well as atomic force microscopic (AFM) images of poly( $\left.\mathbf{2}_{\mathbf{2 0}} \mathbf{-} \mathbf{b}-\mathbf{-} \mathbf{b}_{\mathbf{4 0}} \mathbf{0}\right)$. Absorption (a) and emission (b) spectra of poly $\left(\mathbf{2}_{20}-b-\mathbf{1 b}_{40}\right)$ in the THF/IPA mixture $\left(c=0.3 \mathrm{mg} / \mathrm{mL}\right.$ and $\left.\lambda_{\text {exc }}=365 \mathrm{~nm}\right)$. Insets show images of poly $\left(\mathbf{2}_{20}-b-\mathbf{1} \mathbf{b}_{40}\right)$ in IPA and THF under room light (a) and UV light at $365 \mathrm{~nm}$ (b). AFM height images of poly $\left(\mathbf{2}_{20}-b-\mathbf{- 1} \mathbf{b}_{40}\right)$ cast from THF (c) and IPA (d) solutions onto silicon wafers.

$365 \mathrm{~nm}$, poly $\left(\mathbf{2}_{20}-b-\mathbf{1} \mathbf{b}_{40}\right)$ showed weak and strong emissions in short- (400-500 $\mathrm{nm})$ and long-wavelength $(500-700 \mathrm{~nm})$ regions, respectively, with the maximum emission located at $\sim 570 \mathrm{~nm}$ (Fig. 7b). The emission in the long-wavelength region was gradually quenched after the addition of IPA, whereas that in the short-wavelength region increased. In pure IPA, the block copolymer showed emissions only in the short-wavelength region, with the maximum emission located at $\sim 420 \mathrm{~nm}$, thus exhibiting a blue emission. The solvent-induced optical changes were attributed to the solvophobic effect of the amphiphilic copolymer in selective solvents, affording distinct supramolecular architectures $^{51,52}$.

The self-assembled morphologies of the block copolymer were studied using atomic force microscopy (AFM). Poly $\left(\mathbf{2}_{20}-b-\mathbf{1} \mathbf{b}_{40}\right)$ was self-assembled into nanofibers in THF with a diameter of $\sim 60 \mathrm{~nm}$ and a constant length of up to several micrometers (Fig. 7c), whereas it was self-assembled into spherical nanoparticles in IPA with a diameter of $\sim 30 \mathrm{~nm}$ (Fig. $7 \mathrm{~d}$ ). These results suggest that the absorption and emission changes were probably attributed to different self-assembled architectures, consistent with the findings reported in the literature ${ }^{13,51,52}$. In nonselective THF, the block copolymer showed the emission and absorption of the P3HT block. However, in the presence of IPA, the block polymer self-assembled into compacted spherical nanoparticles. The $\pi$-conjugated structure of the P3TH block was altered during the self-assembly process; thus, the block copolymer exhibited different absorption and emission properties ${ }^{35,51}$. The selfassembled morphology of poly $\left(\mathbf{2}_{20}-b-\mathbf{1} \mathbf{b}_{40}\right)$ in IPA was further confirmed using transmission electron microscopy (TEM) (Supplementary Fig. 31). As expected, the TEM image of the sample cast from poly $\left(\mathbf{2}_{20}-b-\mathbf{1} \mathbf{b}_{40}\right)$ in dilute IPA showed clear core-shell-like spherical nanoparticles with good homogeneity. The average diameter of these nanoparticles was $\sim 32 \mathrm{~nm}$, consistent with AFM investigations. Dynamic light scattering analyses revealed that the hydrodynamic diameter of poly $\left(2_{20}-b\right.$ $\mathbf{1 b}_{40}$ ) was $33.7 \mathrm{~nm}$ in IPA, even at a low concentration of the polymer of $0.3 \mathrm{mg} / \mathrm{mL}$, indicating the self-assembly of the block copolymer in IPA (Supplementary Fig. 32). Note that the 
(a)
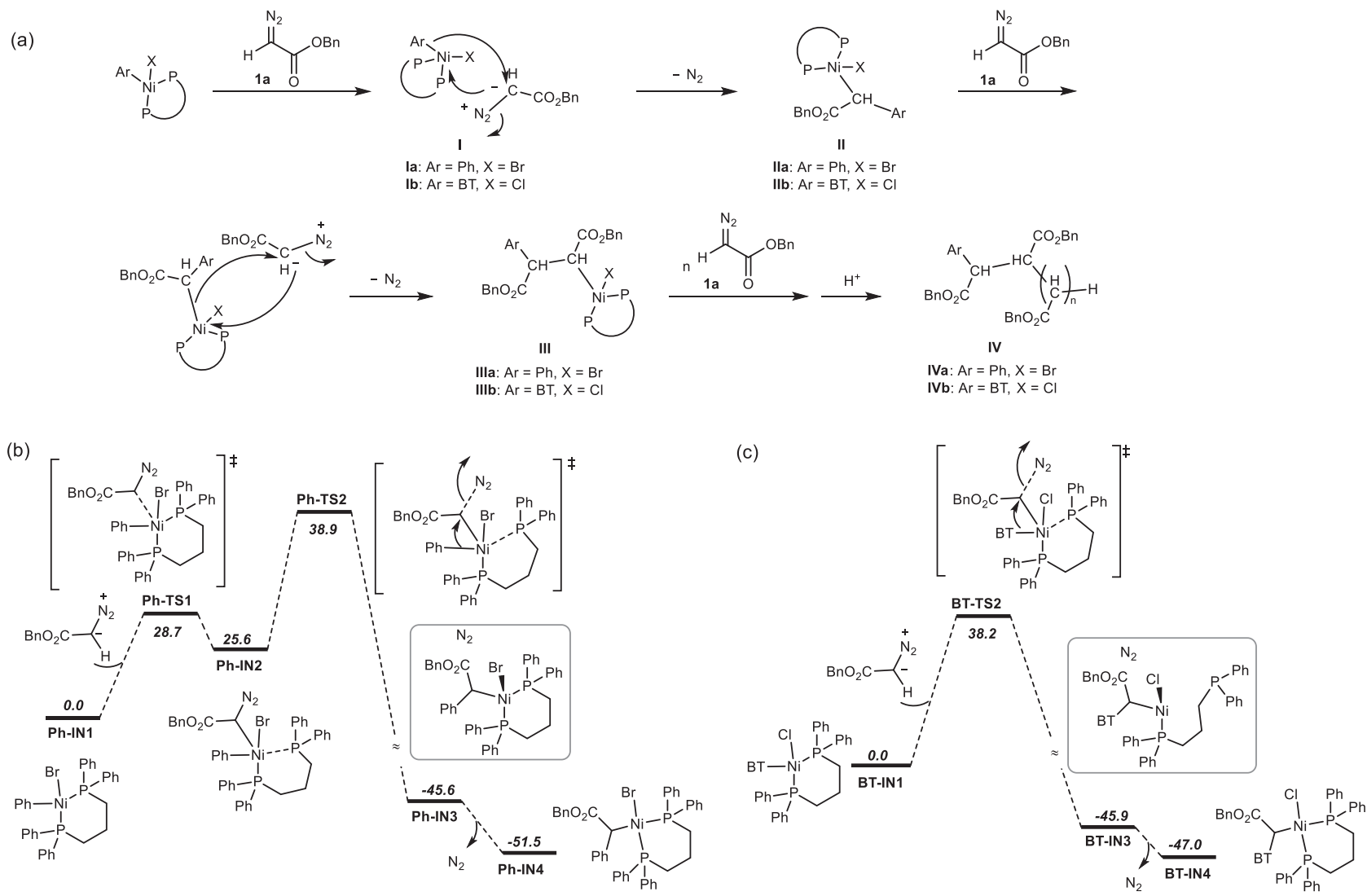

Fig. 8 Proposed polymerization mechanism. a Proposed mechanism for the Ni(II)-mediated diazoacetate polymerization of $\mathbf{1 a}$, and preliminary density functional theory (DFT) calculations for the initiating reaction of $\mathbf{1 a}$ using $\mathrm{Ph}-\mathrm{Ni}(\mathrm{dppp}) \mathrm{Br}$ (b) and $\mathrm{BT}-\mathrm{Ni}(\mathrm{dppp}) \mathrm{Cl}$ (c).

polycarbene block comprised $\mathrm{C}-\mathrm{C}$ bonds and showed densely packed substituents on every backbone atom, rendering it with high rigidity and self-assembly tendency, thereby imparting the P3HT- $b$-polycarbene copolymer with distinct self-assemblyinduced $\mathrm{PL}^{18,21,24}$.

Lastly, the mechanism of $\mathrm{Ni}(\mathrm{II})$-catalyzed living diazoacetate polymerization was proposed ${ }^{27}$. The initiation process was triggered by an attack of an $\alpha$-carbon atom of diazoacetate on the nickel(II) center (Fig. 8). Furthermore, the transfer of Ar in the nickel catalyst onto the $\alpha$-carbon was accompanied by the release of $\mathrm{N}_{2}$. Based on this reaction, the monomer was inserted into the $\mathrm{Ar}-\mathrm{Ni}(\mathrm{II})$ catalyst, affording an intermediate (II). Subsequently, catalyzed using the nickel-complex of II, a new diazoacetate monomer released $\mathrm{N}_{2}$ and the generated carbine was inserted into the $\mathrm{C}-\mathrm{Ni}(\mathrm{II})$, yielding an intermediate III. By repeating the insertion reaction, the polymer chain was propagated. Based on this mechanism, the Ar group in the $\mathrm{Ni}(\mathrm{II})$ catalyst was transferred onto the initiating chain end of the generated polymers. Thus, the $\mathrm{Ni}(\mathrm{II})$-terminated P3HT-catalyzed the living polymerization of diazoacetates afforded expected P3HT- $b$-polycarbene copolymers.

This mechanism was supported using preliminary density functional theory (DFT) calculations (Fig. 8b and c, Supplementary Table 2, and Supplementary Figs. 33-37), which also reveal the different activity of phenyl $\mathrm{Ni}(\mathrm{II})$ catalyst $(\mathrm{Ph}-\mathrm{Ni}(\mathrm{dppp}) \mathrm{Br})$ with BT-Ni(dppp)Cl. Ph-Ni(dppp)Br (Ph-IN1, $0.0 \mathrm{kcal} / \mathrm{mol}$, reference point) coordinated with $\mathbf{1 a}$ via the transition of $\mathbf{P h}$ TS1 $(28.7 \mathrm{kcal} / \mathrm{mol})$ to $\mathbf{P h}-\mathrm{IN} 2(25.6 \mathrm{kcal} / \mathrm{mol})$ (Fig. 8 b). Subsequently, based on a concerted transition state $\mathbf{P h}$-TS2 $(38.9 \mathrm{kcal} /$ $\mathrm{mol}$ ), in which the occurrence of the $\mathrm{C}-\mathrm{N}$ bond cleavage and formation of the $\mathrm{C}-\mathrm{C}$ bond were observed (Supplementary Fig. 33), an intermediate $\mathbf{P h}-\mathbf{I N} 3$ ( $-45.6 \mathrm{kcal} / \mathrm{mol}$ ) was generated.
After releasing $\mathrm{N}_{2}, \mathrm{Br}$ atom went back to the trans-position of the $\mathrm{Ni}(\mathrm{II})$ atom in the P-Ni-P plane, affording Ph-IN4 $(-51.5 \mathrm{kcal} /$ mol). Obviously, the rate-determining step was the concerted $\mathrm{C}-\mathrm{N}$ bond cleavage and $\mathrm{C}-\mathrm{C}$ bond formation processes via $\mathbf{P h}$ TS2. The reaction of BT-Ni(dppp)Cl with 1a was also explored using DFT calculations (Fig. 8c). Unlike in the case of $\mathrm{Ph}-\mathrm{Ni}(\mathrm{dppp}) \mathrm{Br}$, only the key rate-determining step (BT-TS2, $38.2 \mathrm{kcal} / \mathrm{mol}$ ), reactant (BT-IN1, $0.0 \mathrm{kcal} / \mathrm{mol})$, and product BTIN4 $(-47.0 \mathrm{kcal} / \mathrm{mol})$ were obtained, suggesting an irreversible reaction pathway. In BT-TS2, the C-N cleavage also occurred concertedly with the formation of the $\mathrm{C}-\mathrm{C}$ bond (Supplementary Fig. 34). By comparing the reaction pathways between $\mathrm{Ph}-\mathrm{Ni}(\mathrm{dppp}) \mathrm{Br}$ and $\mathrm{BT}-\mathrm{Ni}(\mathrm{dppp}) \mathrm{Cl}$, 1a was found to be was more favorable to react with $\mathrm{Ph}-\mathrm{Ni}(\mathrm{dppp}) \mathrm{Br}$ (Ph-TS2) than with BT-Ni(dppp)Cl (BT-TS2). The ground state of Ph-IN4 (IIa in Fig. 8a) formed more easily and was more stable than BT-IN4 (IIb in Fig. 8a); therefore, the chain extension of 1a using Ph-IN4 was more difficult than that using BT-IN4. Consequently, the expected polycarbenes were obtained with a higher yield and a predictable $M_{\mathrm{n}}$ using the $\mathrm{BT}-\mathrm{Ni}(\mathrm{dppp}) \mathrm{Cl}$ catalyst, whereas polymers with a lower yield and $M_{\mathrm{n}}$ were afforded using the $\mathrm{Ph}-\mathrm{Ni}(\mathrm{dppp}) \mathrm{Br}$ catalyst under identical experimental conditions. Note that the influence of the $\mathrm{Ph}$ and $\mathrm{BT}$ units on the polymerization would decrease considerably with the chain extension because the distance between these units and the living chain end increases.

In conclusion, we developed a $\mathrm{Ni}$ (II) catalyst that can promote the living polymerization of diazoacetates and yield $\mathrm{C}-\mathrm{C}$ main chain polymers with a desired $M_{\mathrm{n}}$ and low $M_{\mathrm{w}} / M_{\mathrm{n}}$. Furthermore, P3HT with a $\mathrm{Ni}(\mathrm{II})$ complex at the chain end can initiate the living polymerization of diazoacetates, yielding well-defined P3HT- $b$-polycarbene copolymers with a tunable $M_{\mathrm{n}}$ and narrow 
$M_{\mathrm{w}} / M_{\mathrm{n}}$. An amphiphilic block copolymer prepared using this method could be self-assembled into distinct nanostructures in selective solvents with unique optical properties. The findings of this study will provide a strategy for the controlled synthesis of $\mathrm{C}-\mathrm{C}$ main chain polymers with polar functionality on every backbone atom and propose an approach for the controlled synthesis of semiconductor materials with great potential in various applications, such as optoelectronics, semiconductor devices, and bioimaging.

\section{Data availability}

Synthetic details and additional experimental data generated in this study are provided in the Supplementary Information.

Received: 2 June 2021; Accepted: 17 January 2022;

Published online: 10 February 2022

\section{References}

1. Ittel, S. D., Johnson, L. K. \& Brookhart, M. Late-metal catalysts for ethylene homo- and copolymerization. Chem. Rev. 100, 1169-1203 (2000).

2. Chen, E. Y.-X. \& Marks, T. J. Cocatalysts for metal-catalyzed olefin polymerization: activators, processes, and structure-activity relationships. Chem. Rev. 100, 1391-1434 (2000).

3. Delferro, M. \& Marks, T. J. Multinuclear olefin polymerization catalysts. Chem. Rev. 111, 2450-2485 (2011)

4. Guo, L., Dai, S., Sui, X. \& Chen, C. Palladium and nickel catalyzed chain walking olefin polymerization and copolymerization. ACS Catal. 6, 428-441 (2016).

5. Chen, Z. \& Brookhart, M. Exploring ethylene/polar vinyl monomer copolymerizations using $\mathrm{Ni}$ and $\mathrm{Pd} \alpha$-diimine catalysts. Acc. Chem. Res. 51 1831-1839 (2018).

6. Caboon, C. R. \& Bielawski, C. W. Metal-promoted C1 polymerization. Coord. Chem. Rev. 374, 261-278 (2018).

7. Jellema, E., Jongerius, A. L., Reek, J. N. H. \& de Bruin, B. C1 polymerisation and related C-C bond forming 'carbene insertion' reaction. Chem. Soc. Rev. 3, 1706-1723 (2010).

8. Luo, J. \& Shea, K. J. Polyhomologation. A living C1 polymerization. Acc. Chem. Res. 43, 1420-1433 (2010).

9. Franssen, N. M. G., Reek, J. N. H. \& de Bruin, B. Synthesis of functional 'polyolefins': state of the art and remaining challenges. Chem. Soc. Rev. 42, 328-5832 (2013).

10. Ihara, E. et al. (N-heterocyclic carbene)pd/borate initiating systems for polymerization of ethyl diazoacetate. Macromolecules 42, 8608-8610 (2009).

11. Long, B. K., Eagan, J. M., Mulzer, M. \& Coates, G. W. Semi-crystalline polar polyethylene: ester-functionalized linear polyolefins enabled by a functionalgroup-tolerant, cationic nickel catalyst. Angew. Chem. Int. Ed. 55, 7106-7110 (2016).

12. Na, Y. \& Chen, C. Catechol-functionalized polyolefins. Angew. Chem. Int. Ed. 59, 7953-7959 (2020).

13. Chu, J.-H., Xu, X.-H., Kang, S.-M., Liu, N. \& Wu, Z.-Q. Fast living polymerization and helix-sense-selective polymerization of diazoacetates using air-stable palladium(II) catalysts. J. Am. Chem. Soc. 140, 17773-17781 (2018).

14. Li, N.-N., Li, X.-L., Xu, L., Liu, N. \& Wu, Z.-Q. Highly enantioselective and helix-sense-controlled synthesis of stereoregular helical polycarbenes using chiral palladium(II) catalysts. Macromolecules 52, 7260-7266 (2019).

15. Zhukhovitskiy, A. V. et al. Dinuclear mechanism implicated in controlled carbene polymerization. J. Am. Chem. Soc. 141, 6473-6478 (2019).

16. Hetterscheid, D. G. H. et al. Rhodium-mediated stereoselective polymerization of "Carbenes". J. Am. Chem. Soc. 128, 9746-9752 (2006).

17. Krappitz, T., Feibusch, P., Aroonsirichock, C., Hoven, V. P. \& Theato, P. Synthesis of poly(glycidyl 2-ylidene-acetate) and functionalization by nucleophilic ring-opening reactions. Macromolecules 50, 1415-1421 (2017).

18. Krappitz, T. \& Theato, P. Comparative study on post-polymerization modification of $\mathrm{C} 1$ poly(benzyl 2-ylidene-acetate) and its $\mathrm{C} 2$ analogue poly(benzyl acrylate). J. Polym. Sci. Part A: Polym. Chem. 54, 686-691 (2016).

19. Ihara, E., Fujioka, M., Haida, N., Itoh, T. \& Inoue, K. First synthesis of poly(acylmethylene)s via palladium-mediated polymerization of diazoketones. Macromolecules 38, 2101-2108 (2005).

20. Ihara, E. et al. $\pi$-AllylPdCl-based initiating systems for polymerization of alkyl diazoacetates: initiation and termination mechanism based on analysis of polymer chain end structures. Macromolecules 45, 6869-6877 (2012).

21. Shimomoto, H., Kudo, T., Tsunematsu, S., Itoh, T. \& Ihara, E. fluorinated poly(substituted methylene)s prepared by Pd-initiated polymerization of fluorine-containing alkyl and phenyl diazoacetates: their unique solubility and postpolymerization modification. Macromolecules 51, 328-335 (2018).

22. Jellema, E., Budzelaar, P. H. M., Reek, J. N. H. \& de Bruin, B. Rh-mediated polymerization of carbenes: mechanism and stereoregulation. J. Am. Chem. Soc. 129, 11631-11641 (2007).

23. Suarez, A. I. O., del Río, M. P., Remerie, K., Reek, J. N. H. \& de Bruin, B. Rhmediated C1-polymerization: copolymers from diazoesters and sulfoxonium ylides. ACS Catal. 2, 2046-2059 (2012).

24. Tromp, D. S., Lankelma, M., Valk, H. D., Jong, E. D. J. D. \& de Bruin, B. Aqueous phase separation behavior of highly syndiotactic, high molecular weight polymers with densely packed hydroxy-containing side groups. Macromolecules 51, 7248-7256 (2018).

25. Walters, A. J. C. et al. Rh-mediated carbene polymerization: from multistep catalyst activation to alcohol-mediated chain-transfer. ACS Catal. 2, 246-260 (2012).

26. Ihara, E., Takahashi, H., Akazawa, M., Itoh, T. \& Inoue, K. Polymerization of various alkyl diazoacetates initiated with ( $\mathrm{N}$-heterocyclic carbene) $\mathrm{Pd} /$ borate systems. Macromolecules 44, 3287-3292 (2011).

27. Shimomoto, H., Ichihara, S., Hayashi, H., Itoh, T. \& Ihara, E. Polymerization of alkyl diazoacetates initiated by $\operatorname{Pd}($ naphthoquinone)/borate systems: dual role of naphthoquinones as oxidant and anionic ligand for generating active Pd(II) species. Macromolecules 52, 6976-6987 (2019).

28. Shimomoto, H., Hohsaki, R., Hiramatsu, D., Itoh, T. \& Ihara, E. Pd-initiated polymerization of dendron-containing diazoacetates to afford dendronized poly(substituted methylene)s with narrow molecular weight distribution and its application to synthesis of $\mathrm{pH}$-responsive dendronized polymers. Macromolecules 53, 6369-6379 (2020)

29. Kato, F. et al. Self-assembly of hierarchiral structures using cyclotriphosphazene-containing poly(substituted methylene) block copolymers. ACS Macro Lett. 7, 37-41 (2018).

30. Mu, H., Pan, L., Song, D. \& Li, Y. Neutral Nickel catalysts for olefin homoand copolymerization: relationships between catalyst structures and catalytic properties. Chem. Rev. 115, 12091-12137 (2015).

31. Yokozawa, T. \& Ohta, Y. Transformation of step-growth polymerization into living chain-growth polymerization. Chem. Rev. 116, 1950-1968 (2016).

32. Nasini, A. G. \& Trossarelli, L. Reactions of diazoalkanes upon metallic surfaces: polymer formation and a stereoregulating action of gold. Makromol. Chem. 44, 550-569 (1961).

33. Ihara, E., Nakada, A., Itoh, T. \& Inoue, K. Transition metal-mediated copolymerization of diazocarbonyl compounds with alkyne and isocyanide. Macromolecules 39, 6440-6444 (2006).

34. Wu, J.-S., Cheng, S.-W., Cheng, Y.-J. \& Hsu, C.-S. Donor-acceptor conjugated polymers based on multifused ladder-type arenes for organic solar cells. Chem. Soc. Rev. 44, 1113-1154 (2015).

35. Shen, X., Hu, W. \& Russell, T. P. Measuring the degree of crystallinity in semicrystalline regioreguar poly(3-hexylthiophene). Macromolecules 49, 4501-4509 (2016).

36. Fukui, T. et al. Seeded self-assembly of charge-terminated poly(3hexylthiophene) amphiphiles based on the energy landscape. J. Am. Chem. Soc. 142, 15038-15048 (2020).

37. $\mathrm{Xu}, \mathrm{L}$. et al. Crystallization-driven asymmetric helical assembly of conjugated block copolymers and the aggregation induced white-light emission and circularly polarized luminescence. Angew. Chem. Int. Ed. 59, 16675-16682 (2020).

38. Tkachov, R., Senkovskyy, V., Komber, H., Sommer, J.-U. \& Kiriy, A. Random catalyst walking along polymerized poly(3-hexylthiophene) chains in Kumada catalyst-transfer polycondensation. J. Am. Chem. Soc. 132, 7803-7810 (2010).

39. Feng, L. et al. Conjugated polymer nanoparticles: preparation, properties, functionalization and biological applications. Chem. Soc. Rev. 42, 6620-6633 (2013).

40. Han, W., He, M., Byun, M., Li, B. \& Lin, Z. Large-scale hierarchically structured conjugated polymer assemblies with enhanced electrical conductivity. Angew. Chem. Int. Ed. 52, 2564-2568 (2013).

41. Pan, S., He, L., Peng, J., Qiu, F. \& Liu, Z. Chemical-bonding-directed hierarchiral assembly of nanoribbon-shaped nanocomposites of gold nanorods and poly(3hexylthiophene). Angew. Chem. Int. Ed. 55, 8686-8690 (2016).

42. He, Y.-J. et al. Facile construction of metallo-supramolecular poly(3hexylthiophene)-block-poly(ethylene oxide) diblock copolymers via complementary coordination and their self-assembled nanostructures. J. Am. Chem. Soc. 139, 4218-4224 (2017).

43. Mosquera, M. A. et al. Exciton absorption spectra by linear response methods: application to conjugated polymers. J. Am. Chem. Soc. 139, 3728-3735 (2017).

44. Jang, H.-J. et al. Analytical platform to characterize dopant solution concentrations, charge carrier densities in films and interfaces, and physical diffusion in polymers utilizing remote field-effect transistors. J. Am. Chem. Soc. 141, 4861-4869 (2019).

45. Loewe, R. S., Ewbank, P. C., Liu, J., Zhai, L. \& McCullough, R. D. Regioregular, head-to-tail coupled poly(3-alkylthiophenes) made easy by the grim method: investigation of the reaction and the origin of regioselectivity. Macromolecules 34, 4324-4333 (2001) 
46. Osaka, I. \& McCullough, R. D. Advances in molecular design and synthesis of regioregular polythiophenes. Acc. Chem. Res. 41, 1202-1214 (2008).

47. Ye, S., Cheng, S., Pollit, A. A., Forbes, M. W. \& Seferos, D. S. Isolation of living conjugated polymer chains. J. Am. Chem. Soc. 142, 11244-11251 (2020).

48. Lohwasser, R. H. \& Thelakkat, M. Toward perfect control of end groups and polydispersity in poly(3-hexylthiophene) via catalyst transfer polymerization. Macromolecules 44, 3388-3397 (2011).

49. $\mathrm{Wu}, \mathrm{Z}$-Q. et al. One pot synthesis of poly(3-hexylthiophene)-blockpoly(hexadecyloxylallene) by sequential monomer addition. Chem. Commun. 49, 8069-8071 (2013).

50. Doubina, N., Ho, A., Jen, A. K.-Y. \& Luscombe, C. K. Effect of Initiators on the Kumada catalyst-transfer polycondensation reaction. Macromolecules 42, 7670-7677 (2009).

51. Su, M. et al. Facile synthesis of poly(phenyleneethynylene)-blockpolyisocyanide copolymers via two mechanistically distinct, sequential living polymerizations using a single catalyst. Macromolecules 49, 110-119 (2016).

52. Yu, Z.-P. et al. Polyallene-block-polythiophene-block-polyallene copolymers: one-pot synthesis, helical assembly, and multiresponsiveness. Macromolecules 49, 1180-1190 (2016).

\section{Acknowledgements}

This work is supported by the National Natural Science Foundation of China (NSFC, Grant Nos. 21971052, N.L.; 22071041, Z.W.; 21871073, Z.W.; and No. 51903072, L.Z.). Z.W. and L.Z. thank the Fundamental Research Funds for the Central Universities of China (Grant Nos. PA2019GDPK0057, L.Z.; and PA2020GDJQ0028, Z.W.). L.X. thanks the financial support from the China Postdoctoral Science Foundation (Grant No. 2020M681981, L.X.).

\section{Author contributions}

Z.-Q.W. and N.L. designed and directed the project; L.Z., L.X., and X.S. performed the experiments. L.X. performed the AFM experiments. S.-M.K. performed DFT calculations. Z.-Q.W. and L.Z. wrote the manuscript with input from all other authors.

\section{Competing interests}

The authors declare no competing interests.

\section{Additional information}

Supplementary information The online version contains supplementary material available at https://doi.org/10.1038/s41467-022-28475-6.

Correspondence and requests for materials should be addressed to Zong-Quan Wu.

Peer review information Nature Communications thanks Bas de Bruin and the other, anonymous, reviewer(s) for their contribution to the peer review of this work. Peer reviewer reports are available.

Reprints and permission information is available at http://www.nature.com/reprints

Publisher's note Springer Nature remains neutral with regard to jurisdictional claims in published maps and institutional affiliations.

(c) (i)

Open Access This article is licensed under a Creative Commons Attribution 4.0 International License, which permits use, sharing, adaptation, distribution and reproduction in any medium or format, as long as you give appropriate credit to the original author(s) and the source, provide a link to the Creative Commons license, and indicate if changes were made. The images or other third party material in this article are included in the article's Creative Commons license, unless indicated otherwise in a credit line to the material. If material is not included in the article's Creative Commons license and your intended use is not permitted by statutory regulation or exceeds the permitted use, you will need to obtain permission directly from the copyright holder. To view a copy of this license, visit http://creativecommons.org/ licenses/by/4.0/.

(C) The Author(s) 2022 